\title{
Rotating Machine Based DG Islanding Detection Analysis Using Wavelet Transform
}

\author{
Lucas Ongondo Mogaka ${ }^{1}$, D. K. Murage ${ }^{2}$, Michael Juma Saulo ${ }^{1}$ \\ ${ }^{1}$ Electrical and Electronics Department, Technical University of Mombasa, Mombasa, Kenya \\ ${ }^{2}$ Electrical and Electronics Department, JKUAT, Nairobi, Kenya
}

Email address:

mogaka.Lucas@gmail.com (L. O. Mogaka),dkmurage25@yahoo.com (D. K. Murage), michaelsaulo@yahoo.com (M. J. Saulo)

\section{To cite this article:}

Lucas Ongondo Mogaka, D. K. Murage, Michael Juma Saulo. Rotating Machine Based DG Islanding Detection Analysis Using Wavelet Transform. International Journal of Energy and Power Engineering. Vol. 4, No. 5, 2015, pp. 257-267. doi: 10.11648/j.ijepe.20150405.14

\begin{abstract}
The increased use of distributed generation in the power system due to increased load demand has brought about many benefits to the power grids. This is due to the concerns about whether the technology in use currently in power generation and distribution, is sufficient to cover the future increasing demand with the limited supply. In response to this problem of increased load demand, efforts have been made to decentralize this infrastructure through the use of distributed generators. The benefits of using distributed generation include; improved reliability and increased efficiency in power supply, avoidance of transmission and distribution capacity upgrades, improved power quality and reduced line losses, minimize peak load demand, reduce voltage flicker, eliminate the need of having high spinning reserve among others. Despite these advantages, un-intentional islanding remains a big challenge and has to be addressed in integration of Distributed Generation to the power system. Unlike inverter based distributed generators, rotating machine based generators with fast response governors and AVRs are highly capable of sustaining an island. Therefore, anti-islanding protection for these generators is a more challenging problem in comparison with the inverter-based DG. This paper analyses the use of wavelet transform in islanding detection for rotating based distributed generators.
\end{abstract}

Keywords: Distributed Generation, Islanding Detection, Rotating Machines

\section{Introduction}

Electric rotating machinery can be defined as any form of apparatus which has a rotating member and generates, converts, transforms, or modifies electric power, such as a motor, generator, or synchronous generator. Although there are many variations, the two basic rotating machine types are synchronous and induction machines.

The current trend in the increasing use of Distributed Generation (DG) is due to energy exhaustion, efforts to improve power quality, reduce the need of having high spinning reserves in the system, reduction of the voltage flickers in the system and recent environmental issues. This practice enables the collection of electrical energy from a variety of sources and leads to decreased environmental impacts and improved security of supply. They are typically in the range of $1 \mathrm{~kW}$ to $10,000 \mathrm{~kW}$ and include wind farms, micro hydro turbines, photovoltaic (PV) system and other small generators which are supplied with biomass or geothermal fuel [1].
Among the many advantages of DG integration include: improved system reliability in the power supply, reduction of system peak loads, spinning reserve size reduction, increased efficiency, avoidance of transmission capacity upgrades, improved power quality, security and reduced transmission line losses and environmental benefits (excluding diesel reciprocating engines often used as back-up distributed generators which tend to be the worst performers in terms of greenhouse gas emissions [2]).

Despite the above mentioned merits of incorporating DGs in the distribution system, it has major drawback of unintentional islanding. Islanding condition occurs when the DG continues to power a part of the grid system even after the connection to the rest of the system has been lost, either intentionally or unintentionally. The unintentional islanding mode of operation is not desirable because of a number of reasons. For instance; it poses a threat to the line workers' safety, the islanded system may not be properly grounded resulting in high voltage in the other phases when an earth fault occurs, possibility of creating an ungrounded system depending on the transformer connections and most 
importantly, the distributed generators may not be able to maintain the voltage and frequency within desired limits in the distribution system when it is islanded.

The rest of the paper is organized as follows; section II discusses the general islanding detection methods, then the various recent islanding detection methods are covered in section III, the islanding detection methods assessment tools for rotating machine based generators are explained in section IV, Methodology for this study in section V, section VI discusses the results and analysis and finally the conclusion in section VII.

\section{General Islanding Detection Methods}

As per IEEE standard 1547-2003, the distributed generators must sense the unplanned power grid and trip it within two seconds, failure to which may lead to several problems in terms of power quality, safety and operational problems [3].

Most of the commonly used islanding detection methods are suitable for all generators and hence the synchronous and induction machines. The general islanding detection techniques can be categorized as shown in the following diagram.

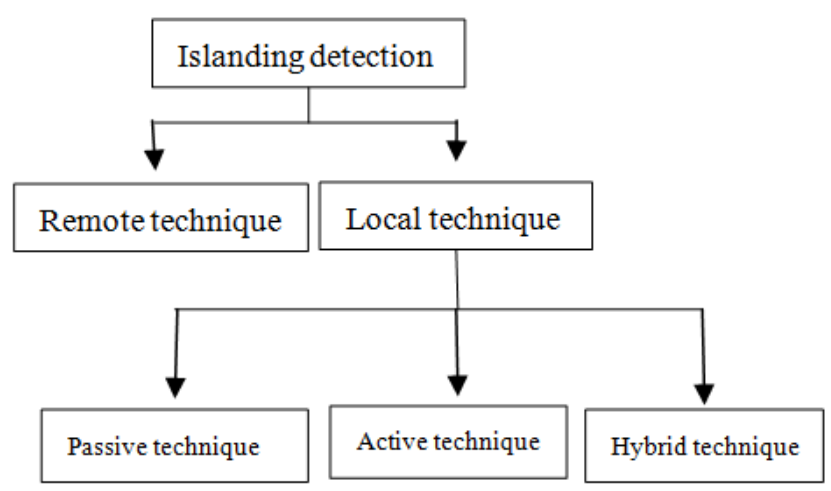

Figure 1. Islanding detection techniques [4].

\subsection{Remote Methods}

This is a method of islanding detection for the DG through communication by the transmitters and receivers located in the power utility and the DG sides respectively. This is achieved though continuous signaling between the two ends. In case there is disruption in the grid that hinders this communication, then this leads to the conclusion that islanding has occurred. Examples of remote islanding detection methods are the power line communication (PLC), supervisory control and data acquisition (SCADA), transfertrip among others. These methods do not have a nondetection zone (NDZ). In terms of reliability, remote methods are far much better compared with local methods only that it is expensive and thus it is uneconomical to implement especially in small networks.

\subsection{Passive Methods}

Passive islanding detection techniques are preferred in island detection especially when the mismatch between the generated power and the size of the load is very large. However, when the mismatch is very small, it is difficult to detect the islanding state because the variations in voltage or frequency at the point of common coupling (PCC) are also very small [5]. The weaknesses of some of the passive islanding detection methods are highlighted in the table 1.

Table 1. Passive islanding detection [6].

\begin{tabular}{|c|c|c|}
\hline Method & Implementation speed & Weakness \\
\hline $\begin{array}{l}\text { UFP/OFP } \\
\text { UVP/OVP }\end{array}$ & $\begin{array}{l}\text { Easy but reaction time } \\
\text { unpredictable and } \\
\text { variable }\end{array}$ & $\begin{array}{l}\text { Large non-detected zones } \\
\text { (NDZs) }\end{array}$ \\
\hline $\begin{array}{l}\text { Phase jump } \\
\text { detection } \\
\text { (PJD) }\end{array}$ & $\begin{array}{l}\text { Difficult in } \\
\text { implementation and hard } \\
\text { to choose threshold }\end{array}$ & $\begin{array}{l}\text { Fails to detect islanding } \\
\text { when DG power generation } \\
\text { matches the power demand } \\
\text { of local load }\end{array}$ \\
\hline $\begin{array}{l}\text { Total harmonic } \\
\text { distortion } \\
\text { (THD) }\end{array}$ & $\begin{array}{l}\text { Easy but hard to choose } \\
\text { threshold }\end{array}$ & $\begin{array}{l}\text { Fails to detect island in case } \\
\text { of low distortion of voltage } \\
\text { and current output of } \\
\text { inverter or high quality load }\end{array}$ \\
\hline $\begin{array}{l}\text { Voltage } \\
\text { Unbalance }\end{array}$ & & $\begin{array}{l}\text { Not applicable to single } \\
\text { phase system }\end{array}$ \\
\hline
\end{tabular}

\subsection{Active Methods}

On the other hand, as compared to passive methods, the active methods have smaller Non-Detection Zones (NDZ). However they compromise the power quality of the system by injecting small signals at certain frequencies to the system. Some of these methods, their properties and drawbacks are shown in table 2 .

Some of the most common active methods used for islanding detection for synchronous DGs include; reactive power compensation, load fluctuation, impedance measurement, reactive power fluctuation, and QC-mode frequency shift method.

Table 2. Active islanding detection methods [6].

\begin{tabular}{|c|c|c|}
\hline Method & $\begin{array}{l}\text { Implementation } \\
\text { and speed }\end{array}$ & Weakness \\
\hline $\begin{array}{l}\text { Impedance } \\
\text { measurement }\end{array}$ & Easy and fast & \\
\hline $\begin{array}{l}\text { Slip-mode frequency } \\
\text { shift (SMS) }\end{array}$ & Medium and slow & $\begin{array}{l}\text { Ineffective under certain } \\
\text { load eg RLC resonant load }\end{array}$ \\
\hline $\begin{array}{l}\text { Active frequency } \\
\text { Drift (AFD) }\end{array}$ & Easy and medium & \\
\hline $\begin{array}{l}\text { Sandia frequency } \\
\text { shift (SFS) }\end{array}$ & $\begin{array}{l}\text { Difficult and } \\
\text { relatively fast }\end{array}$ & $\begin{array}{l}\text { Problem in power quality, } \\
\text { system stability }\end{array}$ \\
\hline $\begin{array}{l}\text { Sandia voltage } \\
\text { shift(SVS) }\end{array}$ & Medium and fast & $\begin{array}{l}\text { Increase harmonic } \\
\text { distortion }\end{array}$ \\
\hline
\end{tabular}

\subsection{Hybrid Methods}

In short, active and passive techniques have their strong and weak points. Thus these methods are at times merged to benefit from their strong points. This technique is called Hybrid islanding detection [7]. Again, there is no islanding detection scheme currently that can serve all situations in distributed system. Therefore, the method is normally selected according to the nature of the distributed generator [8]. 


\section{Recent Islanding Detection Methods}

Since the islanding condition should be detectected as fast as possible as it is stipulated in the set international standards, researchers are continuously looking for better methods of correctly detecting this condition. To achieve this objective, signal processing tools come in handy in extracting the features from measured signals. Then artificial intelligent tools are used to classify the extracted signals to either islanded or non-islanded condition. The general steps usually followed in determining islanding state classification are shown in figure 2 below.

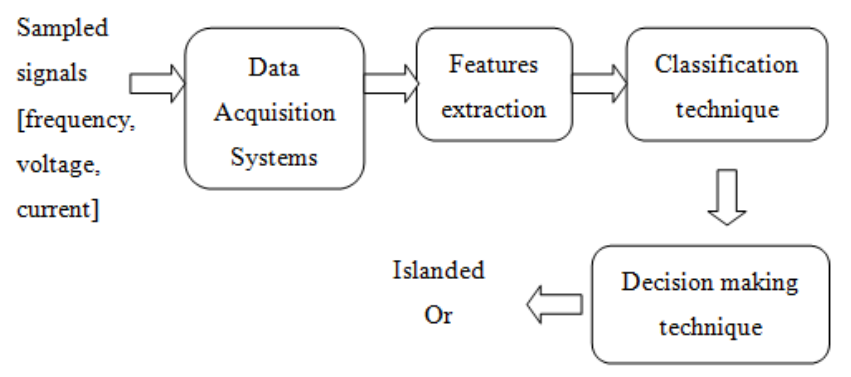

Figure 2. General islanding detection steps.

\subsection{The Wavelet Transform}

A wavelet can be simply defined as a small wave. A wavelet transform (WT) convert a signal into a series of wavelets that are used for analyzing waveforms that are bound in both frequency and time. Alternatively, the WT can be defined as a collection of functions that are used for analyzing non-stationary signals in both frequency and time domains in MATLAB platform. It actually decomposes signals being analyzed layer by layer into different frequency bands for analysis purposes.

It is actually a new mathematical tool developed for analyzing non-stationary and fast changing wide-band signals for instance in islanding detection in synchronous generators. The wavelet transform tool has a number of advantages. One of the main advantage of wavelet transform is that it needs not to assume the stationery or periodicity of a signal as it is able to simultaneously distinguish both time and frequency signal information due to its multi-resolution characteristic. Hence, it becomes useful in analyzing discontinuous and time varying signals especially in islanding detection.

It has three useful properties which make it applicable in engineering applications and most importantly in islanding detection. First, it has ability to reconstruct back the signal from its wavelet transform. This is achieved due to WT ability of the resolution of identity, the ability to conserve energy in the time-scale space and the wavelet admissible condition. Secondly the WT is a local operator in both time and frequency domains. Hence, the regularity condition is usually imposed on the wavelets. Lastly, the WT has a property related to a multi-resolution signal analysis. It has the ability to analyze both high and low frequency signals. The high frequency signal analysis is done using narrow windows and the low frequency analysis is done using wide windows [9].
Wavelet analysis can be categorized into two main techniques. That is; Continuous wavelet transform (CWT) and discrete wavelet transform (DWT).

\subsection{Continuous Wavelet Transform}

The CWT is defined as the sum over all time of the signal multiplied by scaled, shifted versions of the wavelet function. The time-scale information provided by wavelet makes it easy to extract signal features that change with time. Mathematically CWT can be expressed as follows;

$$
\operatorname{CWT}_{X}^{\varphi}(a, b)=\frac{1}{\sqrt{ } a} \int_{-\infty}^{\infty} x(t) \cdot \varphi * \frac{t-b}{a} d
$$

Where: $a$ is the scale parameter of the wavelet, $b$ is the translation or position parameter of the wavelet, $x(t)$ is the analyzed signal, and $\varphi$ is the mother wavelet and is defined by:

$$
\varphi_{a, b}(t)=\frac{1}{\sqrt{ } a} \varphi\left(\frac{t-b}{a}\right)
$$

The CWT is actually continuous in terms of the shift $b$ during calculation and its operation; the wavelet that is used for analyzing the signal is shifted smoothly over the entire domain of the analyzed function. It is actually the measurement of the similarity of the wavelet to the original signal through calculating the coefficient. Thus practically continuous wavelet transform may give redundant information especially when the measured similarity coefficient is large as the original signal and the wavelet will be similar. Hence for the sake of computation, there is need to discretize the signal.

\subsection{Discrete Wavelet Transform}

The discrete wavelet transform (DWT) is found by filtering the low pass and high pass signals successfully. The voltage and current transients of a power system do have unique characteristics that signify the cause of transient occurrence. So there should be a process to extract these features to speed up response in classifying. To this end, wavelet transform seems to be suitable [10].

The discrete wavelet transform is actually the continuous wavelets with the discrete scale and translation factors. Here the wavelet transforms are evaluated at discrete scales and translations. This means that when time localization of the signal is required, the discrete wavelet transform is the one appropriate. This is especially in islanding detection. The DWT function can be defined mathematically as shown in the equation 3 below:

$$
\varphi_{a, b}(t)=|a|^{-\frac{1}{2}} \varphi\left(\frac{t-b}{a}\right) \quad a, b \in R, a \neq 0
$$

If $(a, b)$ take discrete value in $\mathrm{R}^{2}$, we get DWT. A popular approach to select $(a, b)$ is

$$
\begin{gathered}
a=\frac{1}{a_{0}^{m}}, a_{0}=2, \\
a=a_{0}^{-m}=<1, \frac{1}{2}, \frac{1}{4}, \frac{1}{8}, \ldots>, m: \text { integer }
\end{gathered}
$$




$$
\begin{gathered}
b=\frac{n b_{o}}{a_{0}^{m}}, a_{0}=2, b_{o}=1 \\
b=\frac{n}{2^{m}}, \mathrm{n}, \mathrm{m}: \text { integer }
\end{gathered}
$$

Then

$\varphi_{a, b}(t)=|a|^{-\frac{1}{2}} \varphi\left(\frac{t-b}{a}\right)=2^{\frac{m}{2}}\left(\frac{t-\frac{n}{2^{m}}}{\frac{1}{2^{m}}}\right)=2^{\frac{m}{2}} \varphi\left(2^{m} t-n\right)$

Generally, it is a requirement that the response time of the islanding detection method should be shorter hence a lower decomposition level should be selected.

The following are some of the merits that make DWT applicable in islanding detection in synchronous and induction generators. a) It gives enough information for analysis purposes

b) It sufficiently lowers the computation time

c) Its implementation is easy

d) Analyzes signals in different resolutions at different frequency bands

e) Decompose the signal into a coarse approximation and detail information

The ability of DWT to approximate the signals in various scales corresponding to different resolutions. This is known as multi resolution decomposition. The process can be repeated iteratively by breaking signals into many components of lower resolutions. This produces what is called wavelet decomposition tree. The figure 3 below shows an example of a wavelet decomposition tree.[11]

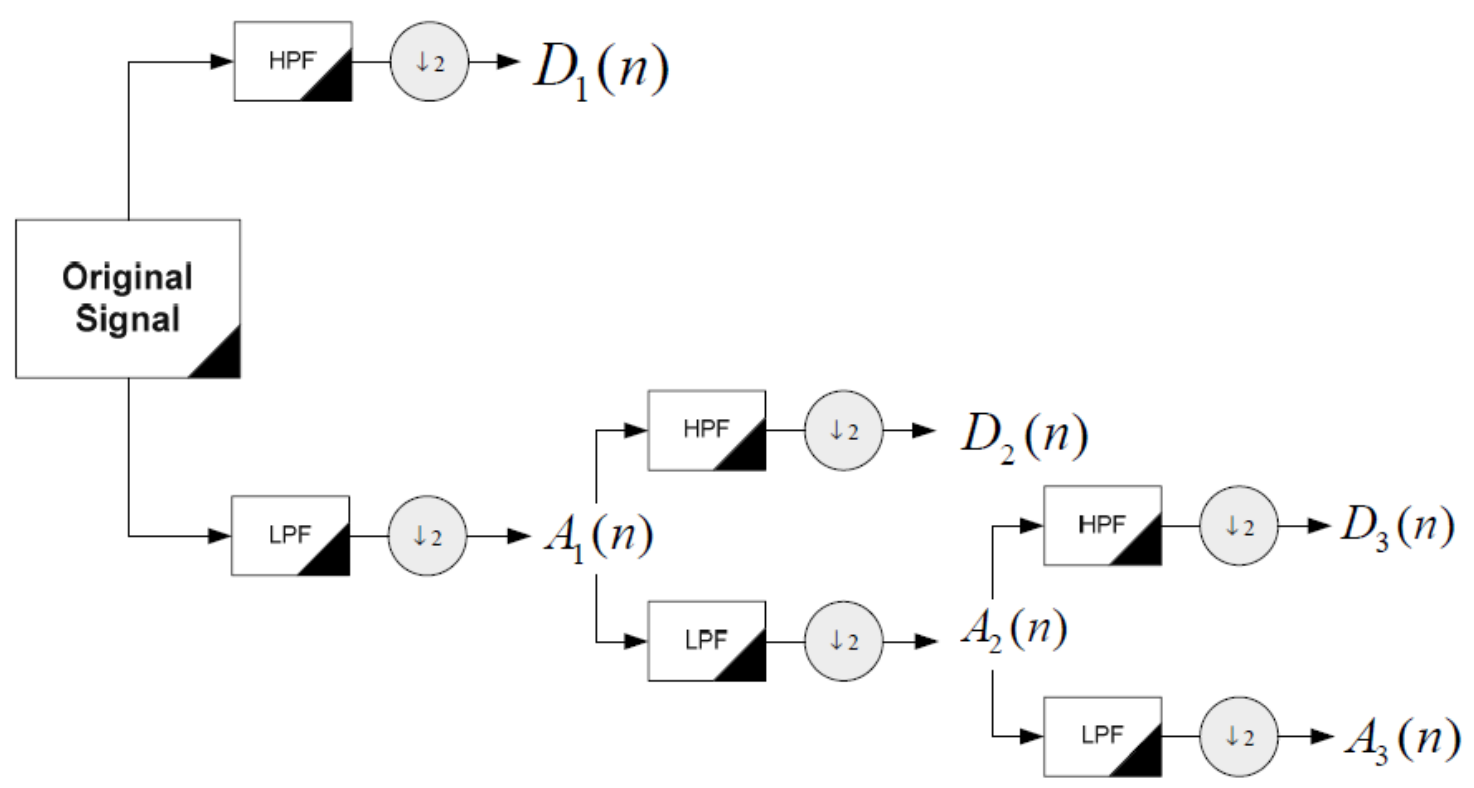

Figure 3. Wavelet decomposition tree.

\subsection{Fuzzy Logic Controller}

A fuzzy logic controller is a control algorithm based on several linguistic control rules and it is used to analyze continuous signals. The fuzzy rule base has the ability to handle more uncertainties in the signal being analyzed that fall along the slope of the fuzzy trapezoidal membership function unlike the crisp classifiers like decision tree which have sharp boundaries, and large data base. Thus, the superior approximation capabilities of the fuzzy systems over crisp classifiers help to develop algorithms that meet the real time application with wide range of uncertainties. Hence the fuzzy logic controller can easily and accurately be used in islanding detection for synchronous and induction generators.

Some of the recent applications of fuzzy logic in islanding detection are as follows; in [12], FL was introduced from the transformation of DT, where the combination of fuzzy membership functions (MFs) and the rule base were used to develop the fuzzy rule base. This technique was easy to implement for online islanding detection and could handle uncertainties such as noise. In [13], however, the band pass filter was used to replace the function of DWT and still worked out pretty well.

\section{Islanding Detection Method Assessment Tools for Rotating Machine Based Generators}

\subsection{Non-Detection Zones}

The effectiveness of any islanding detection method is usually based on the evaluation of the Non-Detection Zone (NDZ) index and the time for islanding detection. Nondetection zones are defined as a loading condition for which an islanding detection method would fail to operate in a timely manner. It is normally evaluated by the use of active and reactive power mismatch space. The non-detected zones for synchronous distributed generators (SDGs) are affected by the following factors among others:
a. Load type
b. generator inertia 
c. generator excitation control mode and

d. relay settings

The following equations (5) and (6) are used to illustrate the definition of the NDZ [14].

$$
\begin{gathered}
\left(\frac{v}{v_{\max }}\right)^{2}-1 \leq \frac{\Delta p}{p} \leq\left(\frac{v}{v_{\min }}\right)^{2}-1 \\
Q_{f}\left[1-\left(\frac{f}{f_{\min }}\right)^{2}\right] \leq \frac{\Delta Q}{p} \leq Q_{f}\left[1-\left(\frac{f}{f_{\max }}\right)^{2}\right]
\end{gathered}
$$

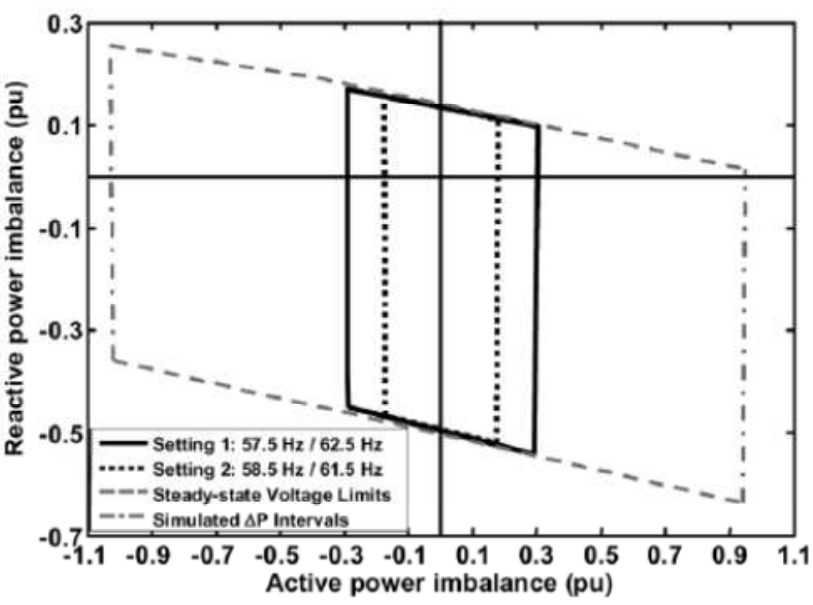

Figure 4. NDZs for different frequency relay settings [15].

\subsection{Performance Curves}

Performance curves represent the relationship between the islanding detection times versus the active power mismatch. This graphical tool is especially useful for synchronous DGs. Power mismatches lower than the critical power imbalance make up, a NDZ, as indicated in Figure 5 below.

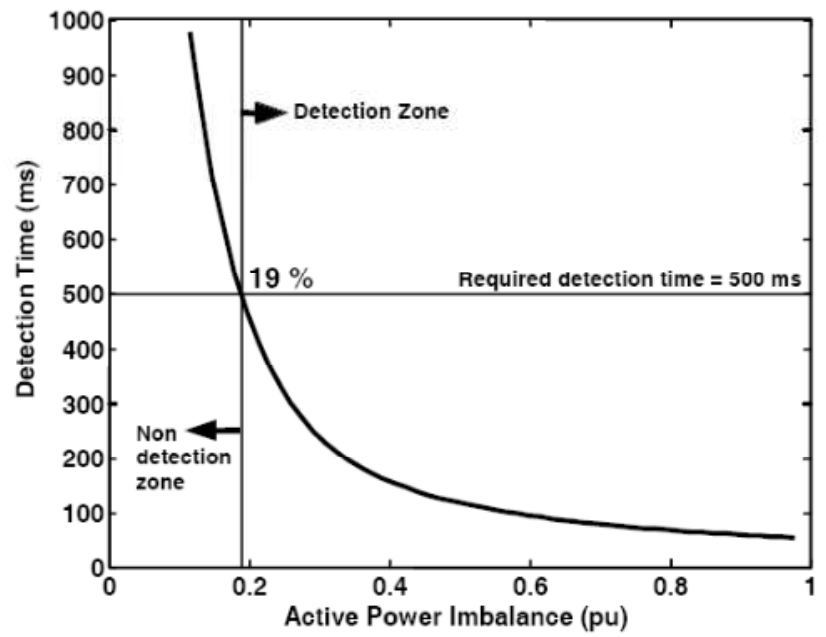

Figure 5. Performance curve of frequency-based relays [15].

In figure 5 above, at the $\mathrm{x}$-axis the active power imbalance level of the islanded system of the generator is represented. Then the island detection time is represented in the y-axis. To obtain this curve the islanding occurrence simulations have to be repeated for some steps. Then, for each active power imbalance, the detection time is determined by dynamic simulation and then the performance curve is plotted [16].

\section{Methodology}

First, the system that was used in this study was modelled in SIMULINK/MATLAB as shown in the figure above.

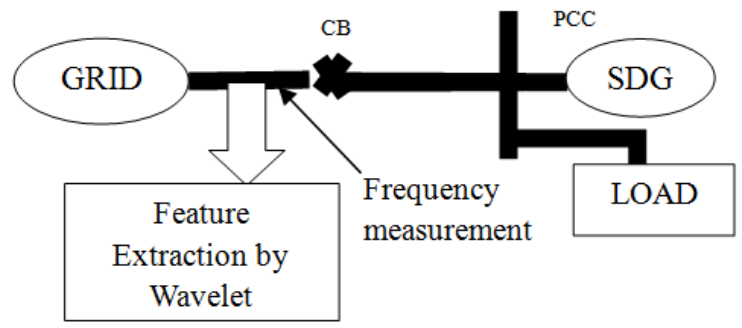

Figure 6. System used for the analysis.

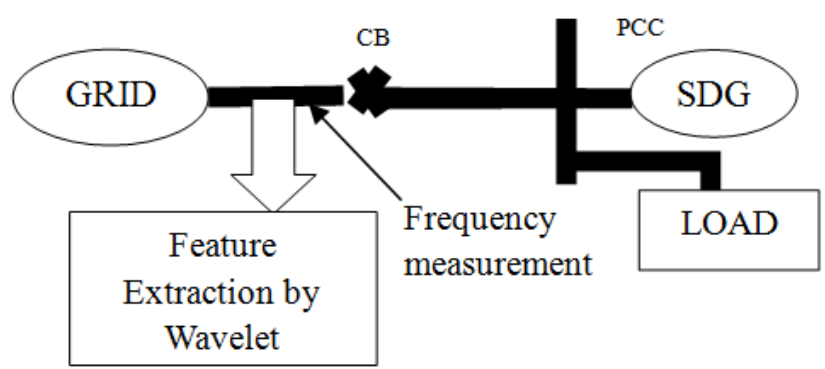

Figure 6. System used for the analysis.

Then the position of measuring the signal frequency was changed to immediately after the utility circuit breaker from the usual point of common coupling. This is meant to make frequency measurement fast and ensure the island detection time is even less than what is stipulated by IEEE 1547-2003 standard. During simulation, the grid was disconnected on the $0.2 \mathrm{~s}$ by switching the three phase breaker off. Then the features of the measured frequency was extracted by discrete wavelet transform (DWT) found in MATLAB toolbox.

\section{Results and Analysis}

First, the combined three phase voltages and currents were measured and are as shown in the figure 7 below. From the figure, it clearly shows that there is remarkable changes on the side of the measured currents as compared with the measured voltages. Thus current measurement was mainly used in the rest of the analysis.

Then, the phase voltages and currents were measured separately for the sake of clarity and are as shown below in figure 8 and 9 .

Then the excitation voltages and currents changes during the disturbance were monitored and are as shown in figure 10 below. It was observed that the excitation currents respond immediately as the fault occurs while the voltage changes gradually.

The current waveform of one phase was discretized during the same period and is as shown in figure 11 below.

And finally, the DWT decomposition of the same signal 
was done up to level 5 and is as shown in figure 12 below.

From the figure above for the DWT, islanding of the micro grid was noted at $2.2564 \mathrm{~s}$.

It can be pointed out from the transform above, that the decomposition of the signal to level 2 (D2) is enough in determining the islanding condition in this case. Thus the islanding detection time is seen to be smaller when a lower decomposition level is chosen.

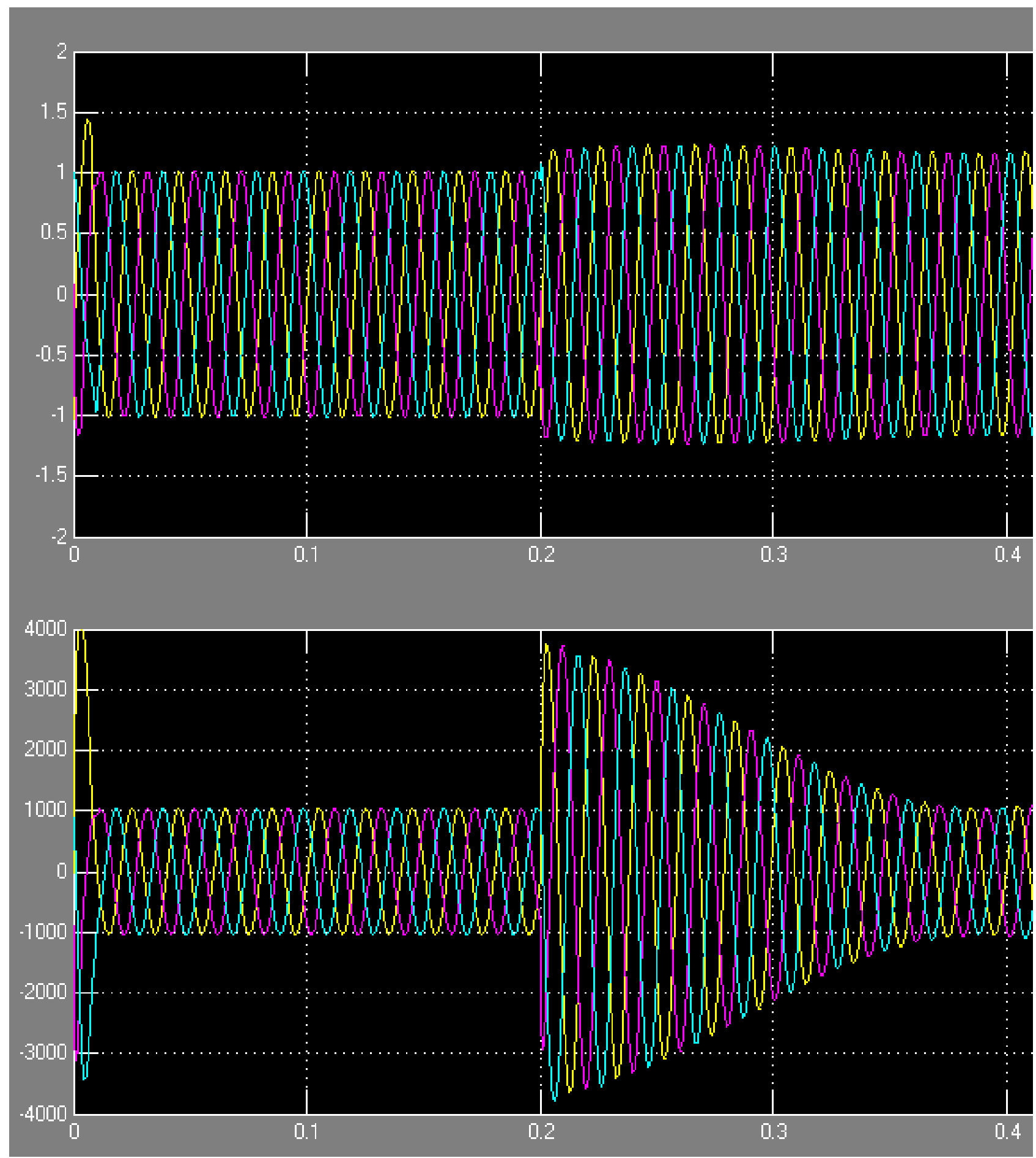

Figure 7. Combined three phase voltage and current measurement. 


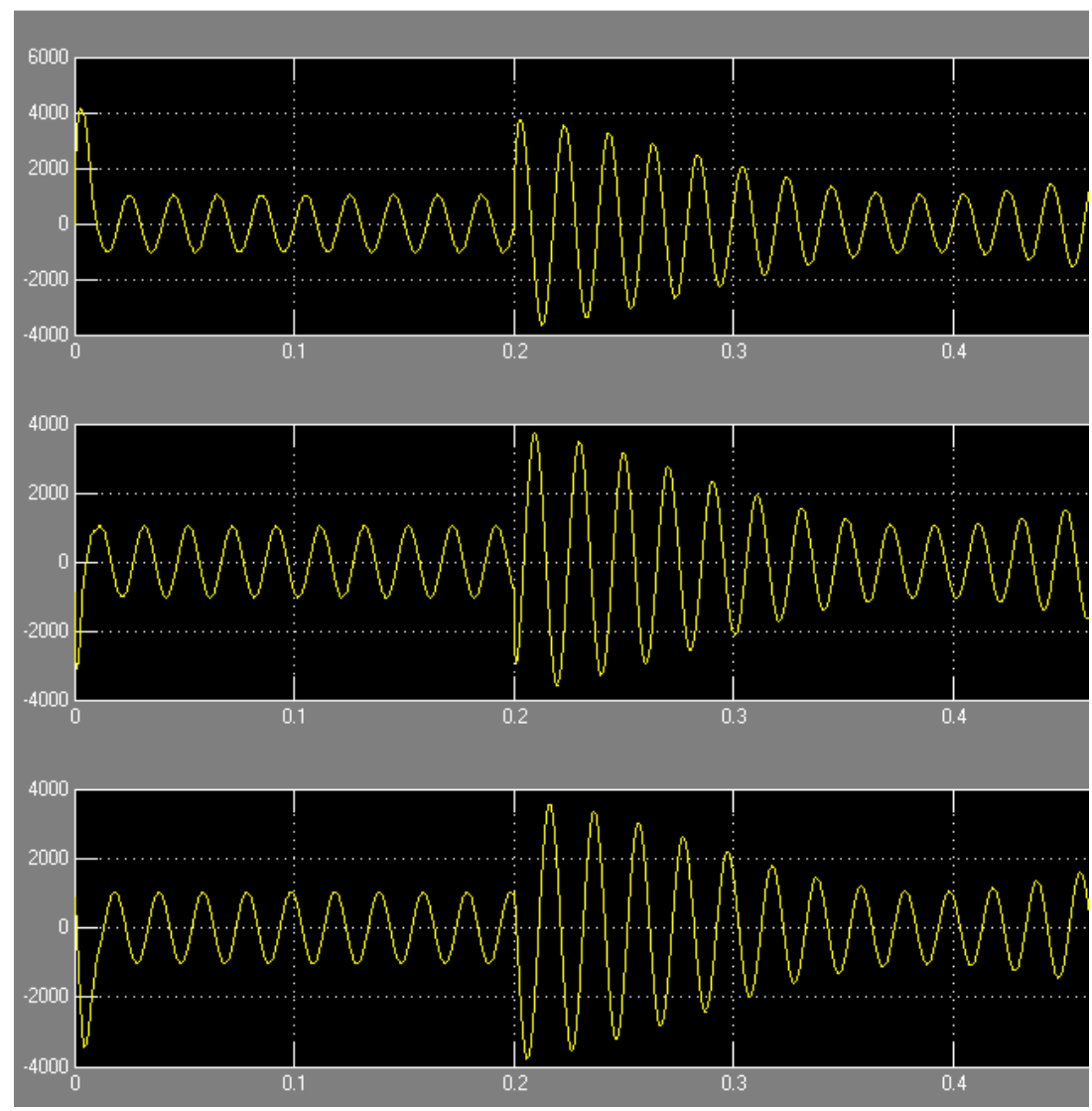

Figure 8. Three phase current measurement.

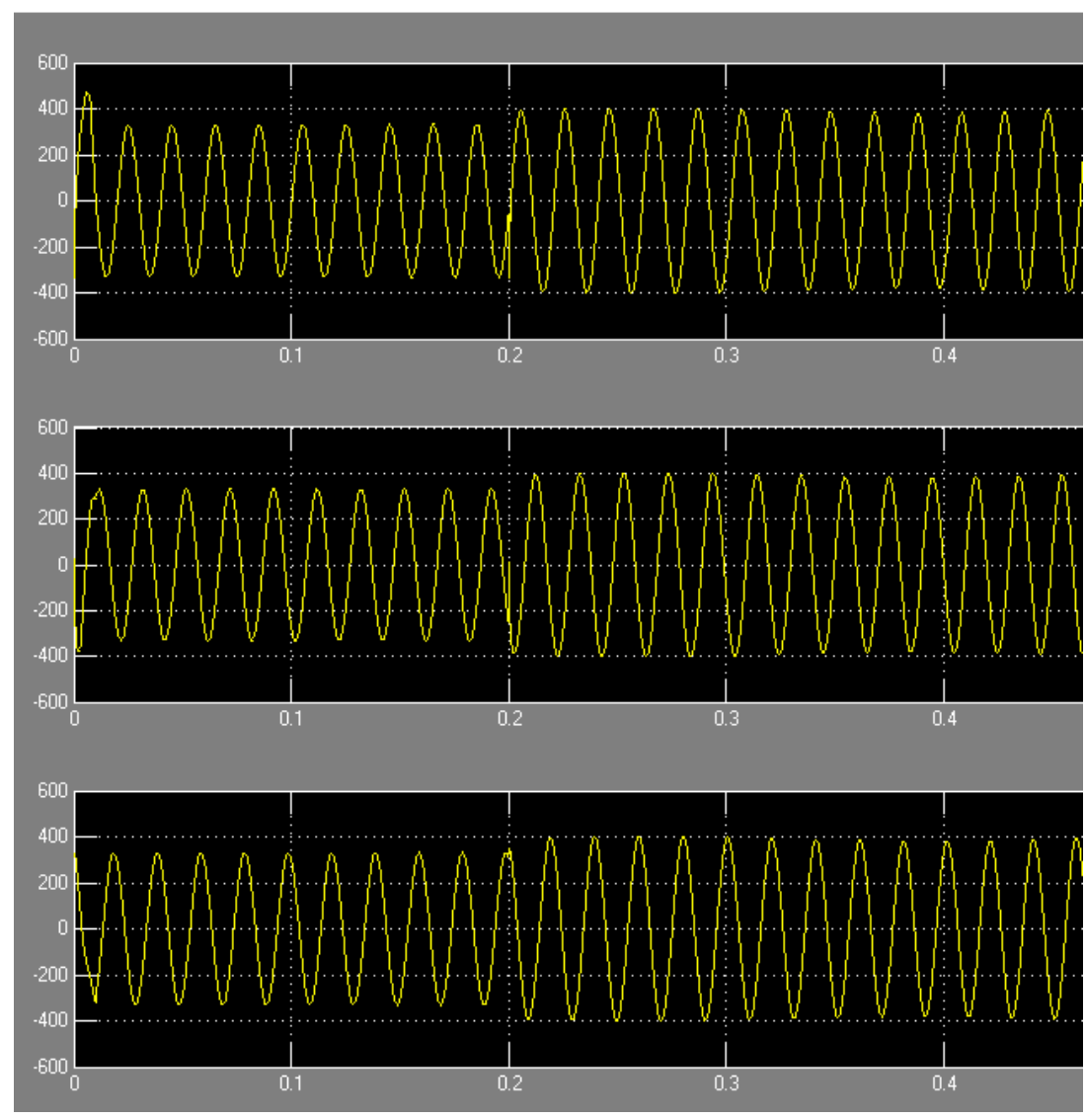

Figure 9. Voltage measurement. 

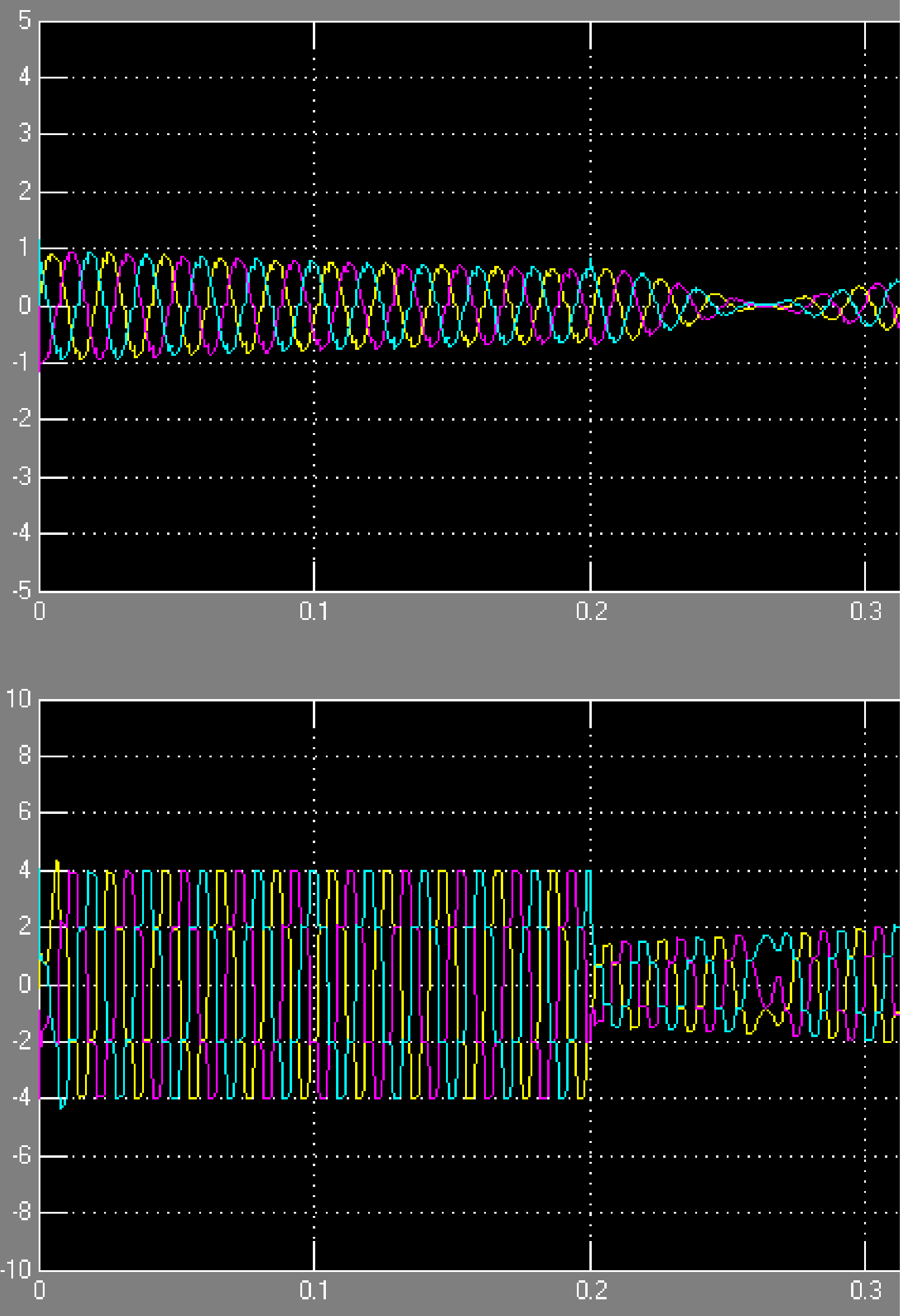

Figure 10. Combined excitation voltage and current. 


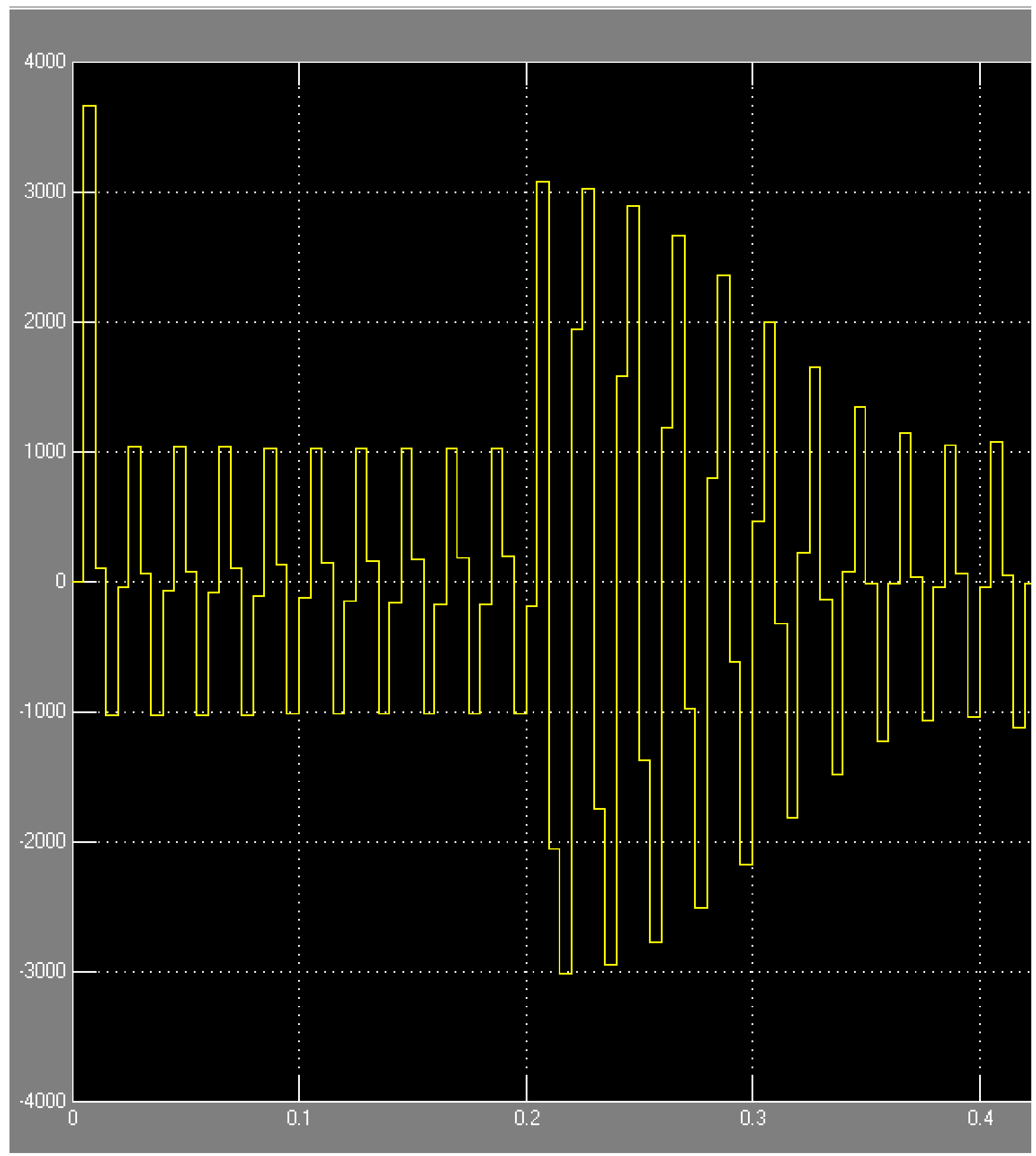

Figure 11. Discrete current signal (RED PHASE). 


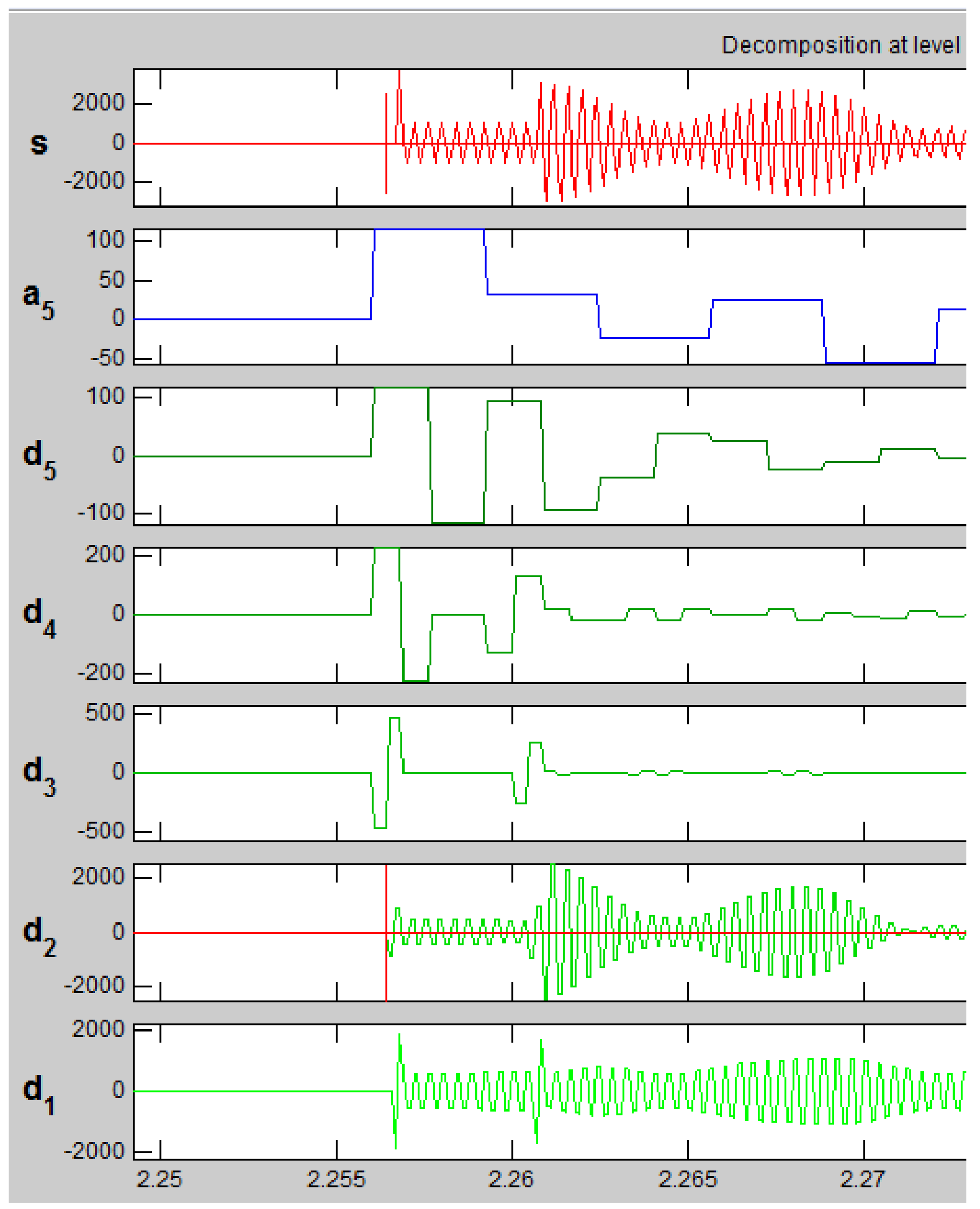

Figure 12. DWT for the analyzed signal.

\section{Conclusion}

Unlike inverter based distributed generators, rotating machine based DGs with fast response governors and AVRs are highly capable of sustaining an island. Therefore, islanding detection and protection for these generators is a more challenging problem in comparison with the inverterbased DG. This paper has analysed the various methods currently used in islanding detection especially for rotating machine based distributed generators especially by use of DWT. It can be seen that there is a quick response to islanding detection due to the changing of the point of measuring of the current signals from the usual PCC to just after the utility circuit breaker. Hence islanding detection time is not affected here by the circuit breaker operation time.

Though the kind of detection can be determined by human 
experts from the diagram, it is desirable to process the obtained wavelet transform results further with artificial intelligence techniques Such as fuzzy logic control [17].

From this analysis, more has to be done especially in islanding detection for synchronous and induction generators so as to increase the power consumer confidence and reliability on the system.

\section{Acknowledgement}

The authors would like to express the greatest gratitude to the Technical University of Mombasa for the continued support from time to time when required.

\section{References}

[1] A. Khamis, "A review of islanding detection techniques for renewable distributed generation systems.," university kebangsaan, malaysia.

[2] J. Martin, "Distributed vs Centralised electricity generation: Are we witnessing a change of Paradigm?," may 2009.

[3] P. mahati, "Review on islanding operation of distribution system with distributed generation," pp. 1-8, 2011.

[4] T. Pujhari, "Islanding Detection In Distributed Generation," 2009.

[5] M. Ashour, "MATLAB/SIMULINK implementation and simulation of islanding detection using passive methods," in IEEE GC conference and exhibition, Dola, 2013.

[6] A. Khamis, "A review of islanding detection techniques for renewable distributed generation systems.," malaysia.

[7] M. Maher and G. M. A. Saad, "'Robust hybrid anti-islanding method for inverter- based distributed generation'".

[8] A. Etxegarai, I. Zamora, P. Eguia and L. Valverde, "A. Etxegarai, I. Zamora, P. Eguia, L. Valverde. Islanding detection of synchronous distributed generators.," in International Conference on Renewable Energies and Power Quality (ICREPQ'12), Santiago de Compostela (Spain), 2012.

[9] Y. Sheng, Wavelet Transform."'The Transforms and Applications Handbook, second edition ed., A. D., Ed., Poularikas Boca Raton: CRC Press LLC, 2000.
[10] H. MEHRDAD, S. GHODRATOLLAH and R. MORTEZA, "An intelligent-based islanding detection method using DWT and ANN.".

[11] O. Mohammed and N. Abed, "Wavelet Transform based islanding characterization method for distributed generation," in Fourth LACCEI international Latin American and Carribean Conference for Engineering and Technology, 2006.

[12] S. Samanta, k. El-arroudi, G. Joós and k. I., "A fuzzy rulebased approach for islanding detection in distributed generation," IEEE Transaction on Power Delivery, pp. 142733, 2010.

[13] J. Pham, N. Denboer, N. Lidula, G. Member, N. Perera and A. Rajapakse, "Hardware implementation of an islanding detection approach based on current and voltage transients.," Electrical power and energy conference (EPEC), pp. 152-157, 2011.

[14] V. Mohammadreza, J. S. Mohammad and B. G. Gevork, "Islanding Detection in Multiple DG Microgird by utility side current measurement," in Internationational Transactions on Electrical Energy Systems, 2014.

[15] A. Etxegarai, I. Zamora, P. Eguia and L. Valverde, "Islanding detection of synchronous distributed generators," in international Conference on Renewable Energies and Power Quality (ICREPQ'12), Santiago de Compostela (Spain), 2012.

[16] W. F. W. X. a. A. M. Jose C. M. Vieira, "Performance of Frequency Relays for Distributed Generation Protection," ieee transactions on power delivery, vol. 21, no. 3, 2006.

[17] K. Oyedoja and O. Obiyemi, "Wavelet Transform in the detection of electrical power quality disturbances," international journal of engineering and applied sciences, vol. 3, no. 2, April 2013.

[18] R. A. Lidula N, "A pattern recognition approach for detecting power islands using transient signals Part I: Design and implementation.," IEEE Transactionon Power Delivery, pp. 3070-7, 2010.

[19] S. B. Karegar H, "Wavelet transform method for islanding detection of wind turbines.," renewable energy, pp. 38:94-106, 2012.

[20] H. Haroonabadi, "Islanding Detection in Micro-Grids Using Sum of Voltage and Current Wavelet Coefficients Energy," International Journal of Energy and Power Engineering, vol. 3, no. 5, pp. 228-236, 2014. 